\title{
En busca de la experiencia perdida
}

\author{
Desiderio Blanco López \\ (Universidad de Lima)
}

Recibido: 3/4/2014

Aprobado: 10/5/2014

Resumen: El presente ensayo plantea de entrada reflexionar sobre la preocupación que obsesiona a Eric Landowski y que se formula explícitamente en Pasiones sin nombre con la pregunta siguiente: «¿Es posible una semiótica de la experiencia?». ¿De esa experiencia viva que consiste en la captación del sentido en su emergencia como pura presencia? Nos proponemos entablar con el autor un intercambio de opiniones sobre la posibilidad de su propuesta, llegando a la conclusión de que no es posible hacer, por ahora, una semiótica de la experiencia viva, en acto. Toda semiótica será siempre sobre un discurso acerca de la experiencia. Dicho discurso, por medio del tratamiento del lenguaje que utilice, será más objetivante o más subjetivante. Cualquier experiencia que pase por el lenguaje, por cualquier lenguaje, verbal o no verbal, será siempre una experiencia segunda, o sea, otra experiencia. Ningún discurso de la experiencia nos devolverá la experiencia primera, la cual será siempre una experiencia perdida.

Palabras clave: experiencia / presencia / interacción / asentimiento

\section{In search of the lost experience}

Summary: This essay aims to reflect on the concern that haunted Eric Landowski and which is explicitly formulated in Passions without a name with the next question: «Is it possible that experience Semiotics can exist?» Through that live experience is that consists the capture of the sense in its emergence as a pure presence? We intend to engage with the author an exchange of views on the possibility of his proposal, coming to the conclusion that it is not possible to talk about, for the time being, Semiotics of the living experience, in act. All Semiotics will always be on a speech about the experience. This speech, by treating the language you use, more objectifying or subjectivating. Any experience that passes through the language, any language, verbal or non-verbal, will always be a second experience, or other experience. No speech experience will return the first experience.

Key words: experience / presence / interaction / assent 
$\mathrm{E}$ n el capítulo V de Passions sans nom, Erick Landowski plantea una inquietante pregunta epistemológica: «¿Es posible una semiótica de la experiencia?». Si la pregunta es nueva, no lo es la preocupación de Landowski por llegar al corazón de lo vivido, al instante mismo de la experiencia en acto. Las trazas de ese recorrido y los aportes teóricos y metodológicos que ha venido haciendo a la semiótica general o sociosemiótica, como él prefiere llamarla, se encuentran diseminados por toda su obra. Con cada nuevo ensayo, con cada nuevo libro, parece que se acerca más a su ansiada meta. ¿Llegará a alcanzarla?

\section{Primeros anuncios}

En La société réfléchie encontramos ya repetidas referencias a lo vivido:

Considerar el discurso como un espacio de interacción es quizás proporcionar el medio de llegar alguna vez a abordar, de un modo no intuitivo, el análisis de las condiciones de existencia y de ejercicio del poder en sus aspectos sociales más evanescentes $y$, sin duda, al mismo tiempo más profundos: es llegar a la formulación y a las fluctuaciones del vínculo social y político con lo vivido (Landowski, 1993, pp. 9-10)

Si se trata de aproximarse a lo vivido, se percibe que las mismas determina- ciones elementales sirven de base a la definición o a la producción de una multitud de efectos situacionales particulares (SF, p. 125).

Para lograr sus objetivos semióticos en pro de una sociosemiótica rigurosamente fundamentada, Landowski necesita elaborar nuevos conceptos teóricos. El primero es el concepto de situación, que introduce ya en esa primera obra. Con el cual resuelve el famoso debate un torno al «contexto», que tantas críticas originó contra la semiótica los años sesenta y setenta. Toda esa polémica se disolvió con la introducción de la noción de situación: «El problema consiste ahora en la 'semiotización' del contexto, mejor dicho, en la elaboración de una semiótica de las situaciones» (SF, p. 200). «Se trata desde el principio de una determinada concepción del 'contexto'. Ni encima ni debajo, sino en el centro mismo del lenguaje» (SF, p. 195).

La situación trae consigo un nuevo concepto operativo: la interacción. Los actantes no están solos, están siempre en el mundo, con otros actantes y antiactantes, con las cosas del mundo que los rodean, tanto naturales como culturales. La interacción es, por tanto, constante en una teoría de la acción. De tal modo que toda acción es siempre una interacción.

Para dar cuenta de los distintos tipos de interacción, E. Landowski crea

1 La sociedad figurada (1993). En adelante, SF, seguida de la página en la versión española. 
modelos adecuados. Se hicieron famosos los modelos que daban cuenta de los regímenes de visibilidad ("Juegos ópticos», SF, p. 129), y los no menos interesantes modelos que permiten comprender el sentido del hacer estratégico: manipular a los hombres versus maniobrar con las cosas; manipular las cosas (como si fueran hombres) versus maniobrar con los hombres (como si fueran cosas).

\section{La presencia: nueva adquisición}

Es evidente que toda interacción requiere la presencia de «otro». Ya sabemos que ese «otro» puede ser una cosa cualquiera con la que podamos interactuar, desde una piedra encontrada por azar hasta una obra de arte, pasando por los individuos y los textos. Pero en esos encuentros de presencias, aletea siempre la esperanza de llegar a lo vivido: «Para efectuar ese recorrido teórico (...) nos esforzaremos por no perder jamás el contacto con la dimensión vivida de las relaciones y de los procesos analizados» (Landowski, 1997, p. 9 [p. 11])².

Con la incorporación de la presencia en forma sistemática a la teoría semiótica, se acentúa también la búsqueda de lo sensible: «Porque sería vano pretender captar las modalidades de la presencia (...) sin contar con la expe- riencia inmediata de lo sensible, de lo figurativo y de lo pasional ligados al aquí-ahora» (PdO, p. 9 [p. 11]).

La presencia semiótica abre el camino a una problemática muy amplia que E. Landowski explora a lo largo de Presencias del otro. El «discurso» que allí se propone analizar no solo es el verbal, sino también el de la mirada, el del gesto, el de la distancia sostenida y otros más. Si todos los estudios incluidos en esta obra son igualmente importantes, hay algunos que destacan por su originalidad y brillantez. En el capítulo II: «Formas de alteridad y estilos de vida», elabora una zoosemiótica imaginaria y de gran potencia explicativa, según la cual las distintas formas de alteridad generan estilos de vida tan singulares como el esnob y el dandy, el camaleón y el oso.

Asimismo, es destacable el capítulo V: «Masculino, femenino, social», donde el análisis recae en imágenes de revistas femeninas con anuncios publicitarios. También aquí, como siempre, en pro del rigor analítico termina elaborando un modelo analítico para organizar y comprender cómo emerge el sentido de tales imágenes: así pasamos de estados «embragados» a estados «desembragados»; de simulacros de «embrague» a simulacros de «desembrague» y simultáneamente, de su-

2 Presencias del otro (1997). En adelante: PdO, seguida de la página de la edición francesa y, entre corchetes, la página de la edición española. 
jetos «socializados» a sujetos «provocadores»; de cuerpos «estetizados» a cuerpos «poseídos».

\section{Consigna decisiva}

En Passions sans nom, E. Landowski arremete de frente con una consigna fundamental: «iDejemos de excluir!». Y lo que hay que dejar de excluir es lo sensible, por supuesto. La semiótica estándar había insistido en separar lo inteligible de lo sensible, separación que por lo demás ha constituido una herencia permanente de la cultura occidental, desde la antigüedad clásica. Bajo esa bandera, Landowski se dispone a recuperar

esas dimensiones perdidas del análisis 'objetivo': la presencia inmediata de las cosas ante nosotros, y la experiencia, esa experiencia de un sentido que procede directamente de nuestro encuentro con las cualidades sensibles inmanentes a las cosas presentes (Landowski, 2004, p. 2 [p. 12]) ${ }^{3}$.

Aparecen aquí nuevas nociones, como la unión y el contagio, conceptos esenciales en la teoría semiótica de Landowski para dar cuenta de esa se- miótica de lo sensible que viene construyendo. Surgen también, en esta importante obra, otras dos nociones que llegarán a su organización e integración más perfecta en una teoría completa de la interacción, la cual será desarrollada en un ensayo posterior titulado Les interactions risquées (2005) ${ }^{4}$. Esas nociones son las de ajuste y accidente, con las que Landowski completa el modelo inicial de la narratividad clásica, insuflándole el soplo vital de la dimensión sensible. Especialmente el ajuste no puede concebirse sin poner en juego la sensibilidad de los actantes de la interacción. También frente al accidente interviene en el sujeto la dimensión sensible en forma de asentimiento (de aceptación resignada), como lo estipula el autor en trabajos posteriores ${ }^{5}$.

$Y$, finalmente, la inquietante pregunta que viene asediando las preocupaciones de Landowski desde hace varios años: «¿Es posible una semiótica de la experiencia?» (PsN, p. 97 [p. 111]). El régimen de sentido que Landowski propone para captar esa experiencia es el régimen del contagio como el más apropiado. Bajo ese régimen, «podría aprehenderse el núcleo, el principio

3 Passions sans nom (2004). En adelante, PSN, seguida de la página del original francés y, entre corchetes, la página de la versión española.

4 Hemos traducido al español y publicado como libro independiente dicho texto: Interacciones arriesgadas (2009). En adelante, $I A$, seguida de la página de la edición española.

5 Véase, por ejemplo, Landowski, E. (2008). Assentiment. En D. Ablali \& D. Ducard, Vocabulaire des études sémiotiques. París: Honoré Champion. Véase también: Une sémiotique à refaire?, 2010. 
dinámico, el 'resorte' de toda forma de experiencia» (PSN, p. 98 [p. 112]). A su vez, el efecto contagioso debe ser referido a determinados modos de existencia del sujeto y del objeto, y sometidos a determinadas operaciones. En un primer momento, señala Landowski, solo se trata de actantes en potencia, situados en el modo potencial de existencia. Para pasar al modo actualizado tendrán que efectuar algunas operaciones semióticas, como percibir la presencia del otro y al mismo tiempo, y gracias a esa presencia, descubrirse a sí mismos como un otro. Por parte del otro, es preciso que ostente una configuración en formación que ofrezca cierta objetividad, o por lo menos alguna positividad. Sobre esa configuración se proyectará el sujeto, se escurrirá por ella y se dejará envolver allí por contagio: (PSN, p. 98 [pp. 112-113]).

\section{Hacia una semiótica existencial}

Fuera de algunos detalles más sobre este planteamiento, no volvemos a encontrar nuevas reflexiones en torno a la inquietante pregunta formulada más arriba hasta el acápite final de Passions sans nom, que lleva por título: «Hacia una semiótica existencial», con el que se cierra el libro. Lo cual es muy significativo porque supone que la cuestión sigue abierta para el autor.

Este breve acápite arranca con una declaración de principios sumamente pertinente:
Sabemos muy bien que no son las cosas como tales las que 'tienen' sentido, o gusto, o los dos a la vez. No es necesario recordar que desde el punto de vista semiótico los efectos de sentido resultan en todos los casos de relaciones diferenciales, es decir, de relaciones entre elementos ( $P_{s} N$, p. 294 [pp. 311-312]).

«¿Cómo entonces construir una semiótica de la relación con las cosas mismas?», se pregunta a continuación el autor. Y postula para contestarse la siguiente metodología: hay que tomar en cuenta para establecer esa relación significante con las cosas mismas dos órdenes de realidad: las diferencias cualitativas de las propiedades sensibles inherentes a las cosas y el régimen de captación del sentido que adopta el sujeto frente a las cosas para hacerlas significar o para encontrarles el gusto (PsN, p. 294 [p. 312]).

Para ilustrar cómo funciona esa metodología, analiza dos fragmentos literarios: uno de Lévi-Strauss y otro de Proust. Lévi-Strauss se coloca ante las cosas como un observador distante, como un científico, digamos; atiende únicamente a las cualidades sensibles de las cosas, y las relaciona entre sí para descubrir su significación. Proust, en cambio, incluye entre los protagonistas de la interacción analizada la instancia de enunciación; el enunciador no solo se implica como observador, sino también como cuerpo comprometido en un juego de relaciones dinámicas con los elementos 
de la escena descrita. En este caso, podemos decir que dichas relaciones hacen sentido. «El texto de Lévi-Strauss se presenta como una descripción organizada por completo a partir de un punto de vista objetivante (...). En cambio, en el breve texto de Proust sobre los «campanarios de Martinville», el observador, en movimiento, pierde el control de la visión, y mientras que las cosas [los campanarios] se ponen a 'mirarlo', él se convierte en un participante directo del juego de relaciones, creando así un punto de vista subjetivante» (PSN, p. 295 [p. 313]).

\section{Nuevos avances en busca de la experiencia}

En un ensayo posterior titulado Une sémiotique à refaire? $(2010)^{6}$, Landowski vuelve a retomar la problemática de la experiencia con otra pregunta inicial: «iHa llegado el tiempo de una semiótica existencial?». El autor remarca lo que dijimos al comienzo del presente artículo: «Esta problemática la venimos considerando desde hace algunos años (...)» (SàR, p. 1 [p. 3]). En este nuevo ensayo relaciona la experiencia con la narración, es decir, la semiótica de la experiencia con la semiótica de la narración. Y siguiendo la consigna promulgada en Passions sans nom, nada de exclusiones. No se excluirá la experiencia sensible en favor de la narración, ni se excluirá la narración en favor de la experiencia. Por supuesto que para Landowski la preferencia la tendrá siempre la experiencia sensible. Pero señala claramente que cada una tiene su estatuto y sus límites.

En todo caso, «vivir», vivir humanamente, es vivir en el sentido. De ahí la primacía que Landowski le asigna a la experiencia del sentido sobre la experiencia de la significación: «La única cuestión que vale la pena: comprender mejor cómo, en qué condiciones, por qué procedimientos nuestra presencia en el mundo llega a tener sentido» (SàR, p. 4 [p. 5]).

Según eso, retoma el modelo de los regímenes de interacción, elaborado en Interacciones arriesgadas (p. 103), y lo reformula a fin de introducir el ajuste y el asentimiento bajo la nueva orientación existencial. Ahora el ajuste y el asentimiento forman la deixis de la experiencia, mientras que la programación y la manipulación se limitan a la deixis de la narración. La gramática narrativa - asegura Landowski- ha colocado en un sitial de honor la figura del manipulador $\mathrm{y}$, más accesoriamente, la del programador.

6 Versión española: Landowski, E. (2011). ¿Habría que rehacer la semiótica? Texto de circulación interna, Universidad de Lima. En adelante, SàR, seguida de la página del texto original y, entre corchetes, la página de la versión española. 
En cambio, ni el sujeto que confía en su capacidad de sentir in vivo las potencialidades de una situación, de convertir en ventaja la 'propensión de las cosas' o de la gente a captar y a explotar el Kairós - bauticémoslo, a falta de mejor término, el oportunista-, ni el fatalista decidido a someterse al azar, encontraron lugar en ese marco (SàR, p. 25 [p. 24]).

De ahí la introducción, al lado de los dos regímenes «estándar» (que, si pierden su monopolio, no pierden nada de su pertinencia [cursivas nuestras]), de los regímenes complementarios fundados, respectivamente, en un principio de sensibilidad y en un principio de suerte [aléa]: el régimen del ajuste (al otro) y el régimen del asentimiento a los decretos de la suerte, a los accidentes de la vida (SàR, p. 25 [p. 24]).

Para esto, y ya desde el ensayo final de Passions sans nom, Landowski se ha desligado del diagrama del «cuadrado semiótico» y ha optado por un diagrama en infinito:
Este diagrama [justifica el autor] ha sido construido a partir de las mismas articulaciones conceptuales que hemos utilizado para organizar el cuadrado semiótico, pero propone una serie de traducciones en términos de recorridos y de estrategias que se interdefinen unos a otros (...). De ahí la forma del diagrama, hecho de curvas continuas, donde las flechas que indican los tránsitos entre las diferentes posiciones se encadenan sin solución de continuidad. Con este gráfico, adaptado a la gradualidad, tratamos de subrayar el hecho de que nos encontramos en presencia de un continuum a lo largo del cual, cada uno de sus elementos puede circular libremente, y al precio de metamorfosis sucesivas, convertirse en otro distinto del que pensaba que era (PsN, pp. 267-268 [pp. 284-285]).

A partir de esa oportuna sustitución, no volveremos a encontrar el cuadrado semiótico en su forma «ortodoxa» en los siguientes escritos del autor.

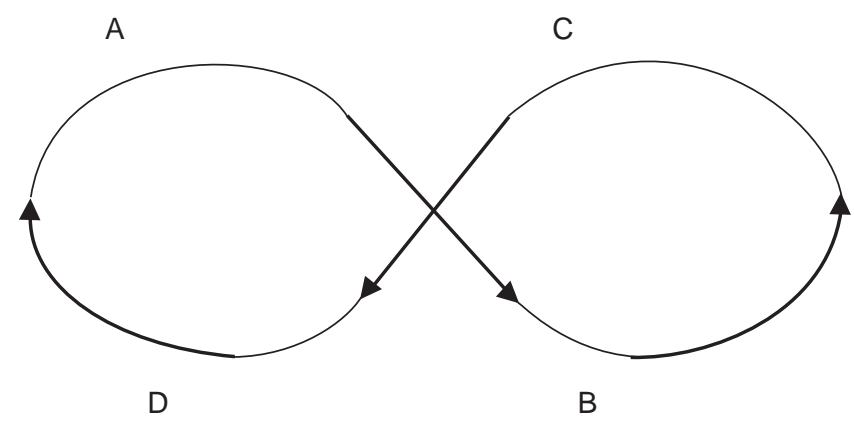




\section{Formas de estar-en-el-mundo}

Según Landowski, los seres humanos adoptan dos formas básicas para mirar el mundo y para hacerlo significar. Las dos son igualmente válidas. Unos miran el mundo como si fuera un texto dispuesto ante nuestros ojos para ser leído. Actitud que nos viene desde san Agustín (La ciudad de Dios); el mundo así dispuesto ante nuestros ojos «quiere decir algo», o en fórmula de Landowski, «tiene significaciones». Hay otros que se dejan llevar por aquello que afecta sus sentidos sin detenerse en descifrar signos preestablecidos ni textos que desentrañar; más bien, se dejan impregnar sin reservas por las impresiones sensibles que les llegan de los seres y de las cosas, dispuestos a captarlas sin que intervengan mediadores de ningún tipo. Se establecen así dos regímenes de ser-en-el-mundo: el régimen de la lectura del mundo como si fuera un texto que tiene significación, y el régimen de la captación impresiva de un mundo vivido en cuanto que $h a-$ ce sentido (SàR, p. 27 [pp. 26-27]).
A estos dos regímenes de actitud ante el mundo corresponden dos estilos de vida existenciales, fundados a su vez en los regímenes de interacción. El lector está programado para manipular, mientras que el captador de lo sensible está orientado en su actividad por el ajuste y el asentimiento.

En este momento de la reflexión, Landowski introduce un importante desdoblamiento en la noción de figuratividad. Por dehiscencia, abre la categoría de figuratividad, que opone a la de narratividad, en dos tipos: la figuratividad stricto sensu, la figuratividad de las «formas figurativas» de superficie, $\mathrm{y}$ la figuratividad lato sensu, figuratividad profunda, figuratividad de las formas rítmicas y plásticas, a la que Lyo$\operatorname{tard}^{7}$ le daba el nombre de figuralidad, término que Claude Zilberberg (1991) retoma para oponerlo igualmente a figuratividad $^{8}$. La figuratividad profunda, o figuralidad, permite, indudablemente, un acercamiento más fino a los fenómenos de lo sensible. Lo figural impone la presencia del sentido tal como emana de las articulaciones plásticas

7 Lyotard distingue tres clases de figura:

a. La figura-imagen: aquella que ofrecen un cuadro de pintura, un filme o una fotografía; esa figura pertenece al orden de lo visible; proporciona los trazos reveladores.

b. La figura-forma: aquella que está presente en lo visible, visible en última instancia, pero, por lo general, no vista; ofrece los rasgos reguladores; es propiamente la figura figural.

c. La figura-matriz: aquella que no solamente no es vista, sino que no es visible. No pertenece al espacio plástico, ni menos al espacio textual: es la diferencia misma. Discurso, imagen y forma carecen de ella, aunque reside en los tres espacios al mismo tiempo. Es, pues, una figura inconsciente (Lyotard, 1971, pp. 277-278).

8 Cl. Zilberberg (1991). «Figura», en A. J. Greimas y J. Courtés. Semiótica. Diccionario razonado de la teoría del lenguaje, t. 2. Madrid: Gredos, entrada: «Figura». 
y rítmicas inmanentes al objeto sensorialmente percibido (SàR, p. 31 [p. 30]).

Hasta aquí llegan, en lo que yo conozco, los avances de Landowski en busca de la experiencia vivida, en acto.

\section{Puntos críticos}

Después de este somero y rápido recorrido por el itinerario semiótico de Eric Landowski, volvamos a la pregunta que nos plantea el autor: « $i$ Es posible una semiótica de la experiencia?». De esa experiencia viva, que consiste en la captación del sentido en su emergencia como pura presencia (PSN, p. 97 [p. 111]).

Nos encontramos aquí con una aporía inversa de aquella con la que se encontró A. J. Greimas al comienzo de su reflexión sobre el sentido: si el universo semántico se identifica con el mundo de la vida en cuyo interior estamos todos «definitivamente encerrados», y si, además, una teoría semántica no puede concebirse más que como una descripción de orden metalingüístico, jerárquicamente distinta de su lenguaje-objeto, no se ve cómo podría tratarse semánticamente el universo englobante que uno se ha dado por objeto, reconociendo que uno mismo está contenido en él. Si ese universo nos incluye, no podremos aprehenderlo «desde fuera» o «desde arriba» como lo prescribe el prefijo de meta-lenguaje (SàR, pp. 5-6 [p. 7]).

Con la experiencia sucede lo contrario: la experiencia vivida, en acto, es un fenómeno instantáneo, fugaz, efímero, inasible. Ningún tercero tiene acceso a esa experiencia vivida en cada instante. $\mathrm{Y}$ aun el sujeto que la vive, que la experimenta, tiene que desdoblarse, si quiere hacer semiótica de su experiencia y convertirse en experimentante y en semiótico al mismo tiempo. El sujeto que lograse hacer esa semiótica no haría semiótica de la experiencia, sino de las huellas sensibles: visuales, auditivas, gustativas, olfativas, plásticas y rítmicas, que las cualidades sensibles han dejado en las diferentes instancias del cuerpo propio. Ya Saussure se adelantó a advertirnos que el significante verbal no eran los sonidos percibidos, sino la imagen acústica. Los sonidos se desvanecen, las imágenes permanecen. Y lo mismo ocurre con las huellas, que no son sino diversos tipos de imágenes. Por otro lado, en el hipotético caso de que el sujeto pudiera controlarlas, la fugacidad de su experiencia reduciría toda semiótica a una auto-semiótica, y su valor científico sería irrelevante para una semiótica que pretendiera obtener un alcance general.

Landowski distingue claramente la vivencia de la experiencia del discurso de la experiencia (SàR, p. 17 [p. 17]). Pero tan comprometido se siente con la vivencia que llega casi a darle a ese «discurso» el valor de la «experiencia» misma. «Ese discurso es, ciertamente, distinto de la vivencia, pero tiene el poder de captar su movimiento y de restituir discursivamente la dinámica de la relación con las cosas, con el otro, 
consigo mismo, en la cual se funda la experiencia del sentido en su emergencia, en acto» (SàR, p. 17 [p. 17]). ¿Y si esa vivencia ha sido meramente imaginada? ¿Quién nos puede asegurar que el escritor Proust vivió la «experiencia de la magdalena»? ¿Quién podría aceptar que las experiencias que vive el M. Goliadkin de Dostoievski fueron vividas por alguien que no sea M. Goliadkin, personaje totalmente inventado por Dostoyevski?

El mismo Proust nos señala el camino del desengaño en un comentario sobre el primer volumen de su gran novela En busca del tiempo perdido. Por el camino de Swann. Respondiendo a una corresponsal que le pregunta por el destino que tendrán sus personajes, dice:

Ya en este primer volumen, ustedes verán que el personaje que cuenta, que dice: 'Yo' (y que no soy yo [cursivas nuestras]) encuentra, de golpe, años, jardines, seres olvidados, en el gusto de un sorbo de té en el que ha remojado un trozo de magdalena 9 .

Es un grave error identificar al narrador con el autor: habitan universos distintos y tienen un estatuto diferente. El narrador es un «personaje» del enunciado, creado por el autor. Vargas Llosa confiesa que

el personaje de una novela más delicado de crear es el narrador. De la oportunidad con que este maestro de ceremonias entre en la historia y salga de ella, del lugar y del momento en que se coloque para narrar, del nivel de realidad que elija para referir un episodio, de los datos que ofrezca u oculte, y del tiempo que dedique a cada persona, hecho, sitio, dependerá exclusivamente la verdad o la mentira, la riqueza o la pobreza de lo narrado ${ }^{10}$.

El narrador nunca es el autor, aunque diga «Yo». Ese «yo» es siempre simulacro del enunciador, el cual es siempre implícito ${ }^{11}$.

A lo largo de la vasta novela, solamente una vez, y solo por hipótesis, Proust sugiere que el narrador podría llevar el nombre del autor. En «La prisionera», muy avanzada la magna obra, encontramos la siguiente situación:

La indecisión del despertar [de Albertina] se revelaba por su silencio, no por su mirada. Al recuperar la palabra, decía: 'Mi' o 'Mi querido' segui-

9 «Déjà, dans ce premier volume, vous verrez le personnage qui raconte, qui dit: 'Je' (et qui n'est pas moi) retrouver tout dans coup des années, des jardins, des êtres oubliés, dans le goût d'une gorgée de thé où il a trempé un morceau de madeleine» [Swann expliqué par Proust], en Contre Sainte-Beuve. Sección «Essais et articles». París: Gallimard, La Pléiade, p. 558.

10 Vargas Llosa, M. (1983). Los miserables: el último clásico. Cielo Abierto, VIII (23), 32-40.

11 Cfr. Blanco, D. (2009). Autor, enunciador, narrador. En D. Blanco, Vigencia de la semiótica y otros ensayos. Lima: Universidad de Lima, Fondo Editorial. 
dos uno u otro de mi nombre de pila, lo que, si le diéramos al narrador el mismo nombre que el del autor de este libro [cursivas nuestras], hubiera sido: 'Mi Marcel', 'Mi querido Marcel' ${ }^{\prime 2}$.

Pero no se lo da, ni antes ni después.

De todos modos, ¿cómo sabe el narrador el nombre del autor, viviendo como viven en mundos diferentes? Ingenioso artilugio literario el que inventa Proust en ese momento: mientras que el autor ha tenido que hacer un largo viaje imaginario hasta toparse con un singular juego japonés que le inspirase la manera de que su narrador trajera a la memoria, con colores y detalles, sus experiencias pasadas con solo saborear un trozo de magdalena empapado en una taza de té, el narrador, como un prodigioso prestidigitador, encuentra ahí mismo la rendija para pasar del universo «literario» en el que habita al mundo «natural» del autor, para conocer su nombre. De otro modo, ¿cómo podría conocerlo? ¡Encantos de la imaginación que permiten tener experiencias totalmente imaginadas! ${ }^{13}$. Y no vividas.

Por otra parte, algunas explicaciones del mismo Proust permiten sospechar que la célebre «experiencia de la magdalena» es un mero recurso literario motivado por la evocación de un juego japonés. En el texto citado más arriba, en el que Proust explica a Swann, añade:

Sin duda, él los recordaba [los jardines, los seres olvidados...], pero sin su color, sin su encanto; yo he logrado hacerle decir [cursivas nuestras] que, como en ese juego japonés en el que uno empapa delgados trozos de papel, los cuales, tan pronto como caen en el tazón, se estiran, se retuercen, se transforman en flores, en personajes, así to-

12 «L'hésitation du réveil, révélée par son silence, ne l'était pas par son regard. Elle retrouvait la parole, elle disait: 'Mon', ou 'Mon chéri' suivis l'un ou l'autre de mon nom de baptême, ce qui, en donnant au narrateur le même prénom qu'à l'auteur de ce livre, eut fait: 'Mon Marcel', ‘Mon chéri Marcel'». Proust, M. (1987). La Prisonnière. En À la recherche du temps perdu, vol. III. París: Rober Laffont, p. 72. (Versión en español: La prisionera. Madrid: Alianza Editorial, 1987, p. 78).

13 Merece la pena recordar aquí que Cervantes se adelantó algunos siglos para hacer algo parecido. En el capítulo II de la segunda parte de Don Quijote, Sancho se entera de que en Salamanca se está hablando de las locas aventuras de su amo: «(...) anoche llegó el hijo de Bartolomé Carrasco, que viene de estudiar en Salamanca, hecho bachiller, y yéndole yo a dar la bienvenida me dijo que andaba ya en libros la historia de vuestra merced, con nombre de El Ingenioso Hidalgo Don Quijote de la Mancha, y dice que me mientan a mí en ella con mi mismo nombre de Sancho Panza (...) y según dice el bachiller Sansón Carrasco (...), jel autor de la historia se llama Cide Hamete Berenjena! [por Benengeli]» (Cervantes Saavedra, M. (2004). Don Quijote de la Mancha. Madrid: Real Academia Española de la Lengua, edición del IV Centenario, Segunda parte, cap. II, p. 565). 
das las flores de su jardín, las ninfeas del Vivonne, y las sencillas gentes del pueblo y sus casitas y la iglesia, y todo Combray con sus alrededores, todo eso que adquiere forma y solidez ha salido, ciudad y jardines, de su taza de té ${ }^{14}$.

De donde se puede inferir que la «experiencia de la magdalena» es totalmente inventada. ¿Valdría menos por eso? ¿Tendría menos sentido?

La diferencia entre el texto de LéviStrauss y el texto de Proust, que analiza Landowski en el capítulo final de Passions sans nom, no se basa en la diferencia de la experiencia, que no la conocemos, se basa en el tratamiento del lenguaje y en el punto de vista que ha adoptado cada escritor para observar los fenómenos. Cualquier experiencia que pase por el lenguaje, por cualquier lenguaje, será siempre una experiencia segunda, o sea, otra experiencia. Por tanto, ningún discurso de la experiencia nos devolverá la experiencia primera, la experiencia vivida, en acto. La experiencia perdida.

Imaginemos una sesión de cata de vino. El catador recibe la copa recién servida; la agita ligeramente, la con- templa al trasluz; observa los reflejos luminosos; luego la acerca a la nariz, aspira dos o tres veces; toma un sorbo, le da unas vueltas en la boca, y finalmente lo expulsa y lo arroja en un recipiente.

Hasta aquí, la experiencia vivida, en acto. Para llevar a cabo esa experiencia, no solamente ha tenido que sentir (ver, oler, gustar), sino que, además, ha debido establecer relaciones (antes, ahora, después), hacer comparaciones entre colores, olores y sabores, a fin de identificar las sensaciones que está sintiendo en cada momento de la experiencia, por breve que sea, pues toda experiencia está constituida por una sucesión de instantes. O sea, ha debido intervenir lo inteligible, por elemental que sea dicha intervención.

Ahora, los catadores comienzan a hablar, es decir, a producir el discurso de la experiencia.

El primer catador dice:
A la vista, intenso color cerezo oscuro; en nariz, aromas de crianza, especias, ahumados y notas de confitura de frutos rojos y negros. Corpulento en boca, sedoso y redondo. Sus taninos suaves y bien fundidos le proporcio- nan un largo y elegante final.

14 «Sans doute il se les rappelait, mais sans leur couleur, sans leur charme; j'ai pu lui faire dire que, comme dans ce petit jeu japonais où l'on trempe de ténus bouts de papier qui aussitôt plongés dans le bol, s'étirent, se contournent, deviennet des fleurs, des personnages, toutes les fleurs de son jardin, et les nymphéas de la Vivonne, et les bonnes gens du village et leurs petits logis et l'église, et tout Combray et ses environs, tout cela qui prend forme et solidité, est sorti, ville et jardins, de sa tasse de thé» [Swann expliqué par Proust], en «Essais et articles», recogidos en Contre Sainte-Beuve, p. 558. 
El segundo catador dice:

Rubí cubierto a la vista, con tonos de terracota y cereza madura. Intenso en nariz, con aromas de frutas rojas, especias y vainilla. En boca, es potente y sabroso, seguido por un final largo de fruta madura y taninos pulidos.

El tercer catador dice:

A la vista, color rojo violáceo profundo; aromas de flores silvestres en nariz; en boca, pimienta negra y tabaco rubio, con notas de chocolate y especias dulces.

El cuarto catador dice:

Color rubí con tonos brillantes y profundos a la vista; en nariz, aromas a ciruelas, cerezas frescas y especias, con un largo final en boca ${ }^{15}$.

Como puede advertirse, el discurso del catador es todo un género literario como otro cualquiera. ¿Qué experiencia vivida podría encontrarse detrás de metáforas como «corpulento en boca, sedoso y redondo [cursivas nuestras]»?, ¿O en aquellas otras como «seguido por un final largo de fruta madura y taninos pulidos [cursivas nuestras]»? Y abriendo el abanico de nuestras inquietudes, ¿qué experiencia vivida, y de quién, podemos descubrir detrás de un poema de Mallarmé como Un coup de dès?, ¿o de un filme de Buñuel como El ángel exterminador?, ¿o de un cuadro de
Velásquez como Las meninas, por no mencionar los de Picasso?, ¿o de un relato como Le Horla de Maupassant?, ¿o de una novela como La guerra del fin del mundo de Vargas Llosa?

De todas maneras, de esos textos de cata podemos inferir lo siguiente:

1. Cada experiencia es singular.

2. Cada catador ha organizado las sensaciones producidas por las cualidades sensibles del vino en forma diferente dentro del género literario establecido.

3. Lo inteligible no se puede separar de lo sensible ni lo sensible de lo inteligible.

4. La experiencia sensible viva, en acto, es inaccesible para la semiótica, por el momento. La semiótica será siempre semiótica del discurso de la experiencia, hasta nuevo aviso.

5. Habrá distintos modos discursivos, distintos «estilos» de organizar el discurso de la experiencia: unos más embragados, otros más desembragados; unos más objetivantes, otros más subjetivantes.

Por lo demás, habría que tener en cuenta que ninguna «configuración sensible y actuante» ( $P_{s} N$, p. 97 [pp. 111-112]) es propia de las cualidades sensibles de los seres y de las cosas. Es

15 Textos recogidos durante una cata real en las bodegas de Ocucaje, diciembre de 2011. Vino catado: Fond de Cave, cosecha 2006. 
el resultado de la operación de percepción, que es ya semiotizante. El puro sentir no organiza los estímulos caóticos, atropellados, que le llegan de las cosas, solamente los siente. La percepción opera en un nivel más elevado que la sensación: la percepción selecciona y combina los estímulos que provienen de la sensación para lograr «configuraciones que hagan sentido». Esta visión es resultado de la docencia del maestro Landowski, del que hemos aprendido que el sentido no está escondido en las cosas como una perla en su concha, sino que es el resultado de una negociación permanente entre un sujeto y un objeto o varios «objetos». En esa negociación interviene ya la percepción, operación que establece diferencias elementales entre las sensaciones provocadas por las cualidades sensibles de los objetos. Por lo tanto, la percepción incluye en sus operaciones un primer grado de inteligibilidad. Lo cual concuerda con la posición central del autor que postula: «iDejemos de excluir!» (PsN, p. 2 [p. 12]). El énfasis y el entusiasmo de Landowski por alcanzar una semiótica de la experiencia vivida, en acto, llegan a producir la impresión de que, ahora, quiere dejar de lado cualquier estela de lo inteligible en lo sensible. En nuestra modesta opinión, todo «sentido» sentido será siempre «sentido» entendido, y si no es entendido, lo sentido jamás hará sentido. A lo sumo, nos encontraríamos, en ese caso, envueltos en un torrente de sensaciones sin sentido. Porque todo sentido surge de operaciones de relación entre diferencias, operaciones que corresponden a la dimensión inteligible del ser humano. Todo «sentido» es siempre construido; nunca está dado de antemano (PdO, p. 12 [p. 14]; SàR, pp. 9-10 [pp. 10-11]). Y menos en las cualidades sensibles de las cosas.

Por último, en toda la obra de E. Landowski no encontramos ni un solo análisis de una experiencia viva, en acto. Todos sus análisis versan sobre obras literarias, de ficción. Incluso en el estudio titulado «Diana in vivo» $\left(P_{S N}\right.$, cap. X), el análisis recae en el «espectáculo» creado por la televisión y no en la experiencia directa, in vivo. Así comienza el ensayo: "Mientras que el espectáculo se desarrolla ante nosotros en la pantalla, la acción tiene lugar en Londres, a comienzos de septiembre de 1997, a las puertas del palacio de Buckingham» (PsN, p. 199 [p. 215]). De aquella acción existencial, el analista no sabe más que lo que le muestra el espectáculo, armado por el discurso televisivo. La impresión de realidad que, por su misma naturaleza, produce el lenguaje audiovisual, es capaz de arrastrar a los espectadores ingenuos. Pero no a Landowski, que sabe distinguir muy bien ambos niveles de «realidad».

No obstante los «puntos críticos» señalados, admiramos el coraje y el tesón con los que Landowski sigue enriqueciendo la teoría y la metodología semióticas y nos contagia su entusiasmo final: «Si la experiencia no es narrable, no por eso es, en principio, menos 
decible, por medio de formas de expresión y de escritura adecuadas, literarias o cinematográficas, y también fenomenológicas, y hasta algún día, por qué no, semióticas» (SàR, p. 38 [p. 37]).

Finalmente, esperemos con renovada esperanza que el incansable semiótico que es nuestro amigo y maestro Eric Landowski logre crear los modelos adecuados para recuperar la experiencia perdida.

\section{Referencias}

Landowski, E. (1989). La société réfléchie. París: Seuil.

Landowski, E. (1993). La sociedad figurada. México: Fondo de Cultura Económica. (Edición francesa: La société réfléchie. París: Seuil, 1989).

Landowski, E. (1997). Présences de l'autre. París: PUF. (Versión en es- pañol: Presencias del otro. Lima: Universidad de Lima, Fondo Editorial, 2007).

Landowski, E. (2004). Passions sans nom. París: PUF. (Versión en español: Pasiones sin nombre. Prepublicación de circulación interna, Universidad de Lima).

Landowski, E. (2005). Les interactions risquées. Nouveaux Actes Sémiotiques, 101-103. [En español: Interacciones arriesgadas. Lima: Universidad de Lima, Fondo Editorial, 2009].

Lyotard, J. F. (1971). Discours, figure. París: Klincksiek.

Vargas Llosa, M. (1983). Los miserables: el último clásico. Cielo Abierto, VIII (23), 32-40.

Zilberberg, Cl. (1991). Figura. En A. J. Greimas \& J. Courtés, Semiótica. Diccionario razonado de la teoría del lenguaje, t. 2. Madrid: Gredos. 